\title{
Clinical and Epidemiological Profile of Oral and Maxillofacial Trauma at Two Quaternary Hospitals in Mozambique in 2016
}

\author{
Nádia Armindo Henriques Fortes, ${ }^{1}$ Prem Yohannan ${ }^{2}$ \\ ${ }^{1}$ Oral and Maxillofacial Surgery Unit, Department of Surgery, Maputo Central Hospital, Maputo, \\ Mozambique \\ ${ }^{2}$ Department of Orthopedic Surgery, Maputo Central Hospital, Maputo, Mozambique
}

Correspondence to: Dr. Nádia Armindo Henriques Fortes; email: nadfortes1@hotmail.com

Received: 13 March 2020; Revised: 11 July 2020; Accepted: 12 August 2020; Available online: 1 September 2020

\begin{abstract}
Background: Our objective was to evaluate the clinical and epidemiological profile of maxillofacial trauma in patients attended to at the Maputo Central and Nampula Central hospitals in 2016. Methods: A descriptive cross-sectional retrospective study based on clinical records of all patients with maxillofacial trauma who attended consultations or were admitted to wards of the maxillofacial surgery services from January to December 2016. Statistical tests looking for significance levels of 5\% were performed in SPSS. Results: Trauma accounted for $482(35.65 \%)$ patients treated at the central hospitals of Maputo and Nampula: of these patients $373(77.4 \%)$ fell in the 15-44-year age group, $363(75.31 \%)$ were male, and $430(89.21 \%)$ were ethnically African. Most patients (259 or 53.77\%) treated at these hospitals were outpatients. The most frequent cause of trauma (albeit without statistical significance) was
\end{abstract}

physical violence. The lower floor of the face was more frequently involved (279 or $57.88 \%$ ), and the most common treatment was closed reduction (238 or 49.38\%). Conclusion: The characteristic clinical and epidemiological profile of patients with maxillofacial trauma is mainly fractures of the lower floor of the face. These types of injuries are usually severe, and developing preventative and multidisciplinary conducts and treatment protocols for these patients is imperative.

Keywords: Epidemiological profile, Maxillofacial trauma, Mozambique

Ann Afr Surg. 2021; 18(2): 85-89

DOI: http://dx.doi.org/10.4314/aas.v18i2.5

Conflicts of Interest: None

Funding: None

(C) 2021 Author. This work is licensed under the Creative Commons Attribution 4.0 International License.

\section{Introduction}

Trauma causes death in all age groups worldwide. The World Health Organization (WHO) reports that trauma is among the leading causes of death and morbidity in the world (1). Maxillofacial trauma is exceptional because it not only has emotional and functional repercussions but can cause permanent deformities to the face (2). Facial injuries are considered a serious public health problem in developed and developing countries $(2,3)$.

Trauma accounts for $20-25 \%$ of admissions to the emergency room. According to the Strategic Plan of Trauma (2008-2014) in Mozambique, it has been observed that with increasing urbanization there is a reduction in certain types of trauma, such as fall from trees, burns, drowning, and even suicide. However, traffic accidents have increased due to alcohol consumption and drug abuse. This has resulted in injuries ranging from simple to complex, that require a 
Profile of Oral and Maxillofacial Trauma

high level of skill and experience for the best treatment results (4-15).

The provinces of Maputo and Nampula are among the most populous in Mozambique. Two public health facilities, Maputo Central Hospital (HCM) and Nampula Central Hospital $(\mathrm{NCH})$, were selected for this retrospective study. They are both quaternary hospitals, HCM being the national reference hospital. This study aimed to assess the clinical and epidemiological profile of oral and maxillofacial trauma in patients attending $\mathrm{HCM}$ and $\mathrm{NCH}$ in 2016.

\section{Methods}

We performed an observational study which was retrospective, transversal and descriptive in character. This study was conducted after approval by the Institutional Bioethics Committee of the Eduardo Mondlane School of Medicine (CIBS FM\&HCM/087/2018). The study was based on clinical records of all patients with maxillofacial trauma including soft tissue and bony injuries, and included all ages and genders, as registered in the outpatient and inpatient registers of HCM and $\mathrm{NCH}$ from 1 January 2016 to 31 December 2016.

We excluded records with incomplete data (case notes without data on the variables under study) and those of any non-traumatic pathologies.

Descriptive results (of the variables of age, sex, race, care, patient condition on arrival) were presented in the form of tables and frequency charts. In the analysis, we sought to establish associations between the different variables being studied: the relationship between age of patients and gender; and the relationship between condition of patient in relation to alcohol consumption and age of patient. Statistical tests using Fisher's and Pearson's (chi-square) methods in SPSS (version 20 for Windows) looked for a significance level of $5 \%$ $(p<0.05)$, which was also used for analysis in this study.

\section{Results}

In a non-random sample of 1352 consecutive patients, the study population was $n=482$ trauma patients.
We performed a univariate analysis of the variables described (Table 1). The age group was stratified according to ICD-10 of the WHO.

Table 1. Causes of maxillofacial trauma at Maputo and at Maputo Nampula Central Hospitals

\begin{tabular}{lcl}
\hline Cause of trauma & Frequency & $\%$ \\
\hline Work-related injury & 7 & 1.4 \\
$\begin{array}{l}\text { Road traffic accident } \\
\text { (collision) }\end{array}$ & 28 & 6.0 \\
Road traffic accidents (runover) & 36 & 7.4 \\
Sports injuries & 16 & 3.3 \\
Physical aggression & 43 & 9.0 \\
Human bites & 10 & 2.0 \\
Unspecified & 342 & 70.9 \\
Total & 482 & 100.0 \\
\hline
\end{tabular}

We observed that $77.39 \%(n=373)$ of trauma patients were aged between 15 and 44 years and only $1.8 \%(n=9)$ were older than 64 years, the youngest patient was 1 year and the oldest was 78 years, the median age was 27 years. The sample had75.31\% $(n=363)$ male and $24.69 \%$ $(n=119) \quad$ female,89.21\% $\quad(n=430) \quad$ were ethnically African,53.73\% $(n=259)$ did not require admission. About $89.42 \%(n=431)$ of the trauma patients had no clinical records specifying whether they had taken alcohol before presenting at the hospital.

At both hospitals, most medical records $(70.90 \%)$ did not comment on the etiology of maxillofacial trauma, but from the few records that did $13.4 \%$ were a result of road traffic accidents (collisions and runovers) and 9\%fromphysical aggression (violence).

Table 2 shows the location of maxillofacial traumas in patients. About 280 injuries (57.88\%) involved the lower floor of the face (jaw) (Table 2). The distribution of mandibular fractures according to anatomical region was studied. Para symphyseal fractures (33\%) and bilateral fractures of the body of the mandible (35\%) together accounted for $68 \%$ of all mandibular fractures. Other fractures involved the jaw angle region (13\%), symphyseal region $(6 \%)$, mandibular condyle $(2 \%)$, and the ascending ramus of the mandible (1\%). 


\section{FORTES AND YOHANNAN}

Table 2. Location of maxillofacial trauma in patients at Maputo and Nampula Central Hospitals

\begin{tabular}{lll}
\hline Location & Frequency & $\mathbf{( \% )}$ \\
\hline Lower floor of the face (jaw) & 279 & 57.88 \\
Middle floor of the face & 52 & 10.79 \\
$\begin{array}{l}\text { Full face traumatized (wounds } \\
\text { scattered across the face) }\end{array}$ & 64 & 13.28 \\
Region of the dental arches & 53 & 11.00 \\
Temporomandibular joint region & 10 & 2.07 \\
Tongue & 24 & 4.98 \\
Total & 482 & 100 \\
\hline
\end{tabular}

For treatment, $49.30 \%(n=238)$ had a closed reduction and intermaxillary fixation (Table 3 ).

Table 3. Treatment performed on trauma patients at Maputo and Nampula Central Hospitals

\begin{tabular}{lll}
\hline Treatment & Frequency & $\mathbf{( \% )}$ \\
\hline Hematoma drainage & 2 & 0.40 \\
Multiple extractions \&alveoloplasty & 17 & 3.50 \\
Open reduction & 65 & 13.50 \\
Closed reduction & 238 & 49.30 \\
Synthesis (suture) & 139 & 28.80 \\
Conservative surgical treatment & 22 & 4.50 \\
Total & 482 & 100 \\
\hline
\end{tabular}

This study analyzed the association between the variables of age and gender with maxillofacial trauma. The age groups were stratified according to WHO ICD10 criteria. Fisher's exact test showed $\mathrm{p}=0.006$, indicating a statistically significant association between age and gender in maxillofacial trauma.

Out of 362 male patients, 289 were between 15 and 44 years, 45 between 1 and 14 years, 26 between 45 and 64 years, and only 2 patients were above 64 years.

The study also analyzed the relationship between the patient's condition in relation to alcohol ingestion at the time of admission and age. Fisher's test $(p=0.091)$ showed no statistical association. Of the 11 patients observed to have consumed alcohol, 9were between 15 and 44 years, 1was between 1 and14 years, and 1between 45 and 64 years.

\section{Discussion}

There are no published studies on the subject for Mozambique with which to compare our findings. This study is the first of its kind in this country and makes available relevant information which can be compared with similar studies from other countries.

The demographic profile of maxillofacial trauma patients in the two hospitals studied in Mozambique in 2016 is similar: most trauma patients are in the 15-44year age group, with a mean age 27 years; maxillofacial trauma is more prevalent in African males.

These results of the variables of age, sex, and race are not very different from studies carried out in Nigeria and South Africa (15). The 15-44-year age group is also the most physically active; it includes students and a large portion of the working population. Particularly in the African context, this age group also includes individuals with significant degrees of social responsibility: many in the group are the sole breadwinners in their respective families. This active age group also has a predilection for consuming alcohol and using recreational drugs. It is more likely than any other age group to frequent social gatherings in bars, clubs, discos, etc. This could justify the findings in this study of the disproportionate prevalence of maxillofacial injury as a result of physical violence and road traffic accidents in the 15-44 years age group. According to the WHO, violence is among the leading causes of death worldwide for people in the 15-44-year age group (1).

This study shows a marked difference in the prevalence of maxillofacial trauma in men and women in the two hospitals, in line with the findings of studies done in South Africa (15).

The prevalence of women with maxillofacial trauma has increased (15). Especially in the last three decades, incidence of trauma is growing in women usually aged up to 40 years. This may be due to the behavioral changes of women in society-a greater number of women drivers, the combination of alcohol and driving, and their being required to drive for work $(3,4,5,16)$.

The lower prevalence of maxillofacial trauma in the vulnerable age groups of 1-14 years and $>64$ years may be due to the decreased incidence of high-risk behavior for trauma in these groups. Maxillofacial fractures have 
been found to be less frequent in children (1-14 years) and in the elderly over the age of 60 years $(3,17-19)$.

We cannot draw conclusions on outpatient or inpatient treatment and on the consumption of alcohol, due to lack of data in this study. In the literature consulted, in all traumas resulting from traffic accidents, the presence of alcohol was noted in $65 \%$ of cases (1).

Studies in Pakistan, South Africa, and Brazil identify physical aggression as the primary cause of maxillofacial traumas $(1,18,19)$; this study cannot yet state conclusively from the few duly completed clinical reports available that physical aggression and traffic accidents are among the leading causes of maxillofacial trauma.

In this study, traumas of the lower floor of the face are the most prevalent types of maxillofacial trauma, mandibular fractures being the most common diagnosis; this finding agrees with the findings of similar studies in the literature consulted (17). The regions of the head, jaw and para symphyseal area of the mandible are the most common locations of these fractures (10-13).

This study also found that closed reductions are the most common treatment, again agreeing with the available literature (7-9,14,15,20). Wound suture and open reductions were also the most frequent treatment modalities used.

\section{Conclusion}

Trauma is a major cause of injury in Mozambique. This study has provided evidence important for public health: in 2016more than one-third of patients treated at the Maxillofacial Surgery Service had maxillofacial trauma. Maxillofacial trauma is one of the leading causes of hospitalization at $\mathrm{MCH}$ and $\mathrm{NCH}$.

The characteristic epidemiological profile of patients with maxillofacial trauma is mainly lower facial floor fractures. This type of trauma is severe and common in males between the ages of 15 and 44 years, who had a similar clinical management in both hospitals in Mozambique.

\section{References}

1. Porter M, Lownie M, Cleaton-Jones P. Maxillofacial injury: A retrospective analysis of time lapse between injury and treatment in South African academic oral and maxillofacial surgery unit. S Afr J Surg. 2013;51(4):138142.

2. Furtado D, Estabile G, Aita T. Facial trauma profile in patient victims of motorcycle accidents. Pananá, Brazil: State University of Londrina. 2015;18.

3. Montovani J, Fields L, Gomes M, et al. Etiology and incidence of facial fractures in adults and children: Experience in 513 cases. Rev Bras Otorrinolaringol. 2006;72(2):235-241.

4. Punjabi S, Khan M, Hassan Q, et al. Associated with facial trauma injuries - a study. J Liaquat University Medical Health Sci. 2012;11(2).

5. Abouchadi A, Taoufik H, Nacir O, et al. Pan facial fractures: A retrospective study and review of literature. Open J Stomatol. 2018;(8)110-119.

6. Matos C. Strategic plan for prevention and control of trauma and violence 2008-2014. Ministry of Health Department of Noncommunicable Diseases, Maputo: Leima Impressions Originals Ltd. 2008.

7. Shah K, Egan D, Quaas J. Essential emergency trauma. Philadelphia, PA: Wolters Kluwer, Williams \& Wilkin Lipppincott Publisher, 2011

8. Manganello-Souza L, Luz J. Maxillofacial surgical treatment of trauma. 3rd Edition. Roca, 2006.

9. Hupp J, Edward E, Tucker M. Contemporary oral and maxillofacial surgery. 5th Edition.Rio de Janeiro, Brazil; Elsevier, 2009.

10. Prado R, Salim M. Maxillofacial surgery diagnosis and treatment. Rio de Janeiro, Brazil: Guanabara Koogan, 2004.

11. Denadai R, Raposo-Amaral C, Marques F, et al. Posttraumatic eyebrow hair-bearing reconstruction with temporoparietal fascia flap. Campinas, SP, Brazil: Institute of Craniofacial Plastic Surgery, Skull Hospital and Face, 2013.

12. Rezende R, Macedo J, Rosa S, et al. Profile epidemiological and treatment of substance loss from trauma in lower limbs. Magazine Col Bras Cir. 2017; 44(50):444-451.

13. Haggerty J, Laughlin M. Atlas of operative oral and maxillofacial surgery. Ames, OH: Wiley Blackwell, 2015.

14. Haerle F, Billeterry C. Atlas of craniomaxillofacial osteosynthesis. Microplates, miniplates and screws. 2nd Edition. New York, NY: Thieme, 2009

15. Desai J, Lownie F, Cleaton J. Prospective audit of mandibular fractures at the Charlotte Maxeke Johannesburg Academic Hospital. S Afr J Surg 2010;48(4):122-126.

16. Bortolini M, Scherbaum J, Engelmann $J$, et al. Maxillofacial trauma: evaluation of 1358 cases of fracture 


\section{FORTES AND YOHANNAN}

face. Rev Cir Traumatol Maxillo-Fac Camaragibe. 2014;14(2):87-94.

17. Peterson L. Cirurgia oral and maxillofacial contemporary. 3rd Edition. Elsevier, 2000.

18. Nicol A, Knowlton L, Schuurman N, et al. An analysis of 9236 consecutive trauma center admissions. JAMA Surg. 2014;149(6):549-556.

19. UNFPA. Social and Demographic Moçambique. Indicadores. Mozambique. www.unfpa.org.mz Accessed on $26 / 10 / 2018$.

20. Dadkhah A, Saied-Moallemi Z, Alem-Rajabi M. Head and face injuries and helmet use among motorcyclists injured with road accidents in Isfahan, Iran. J Oral Health Oral Epidemiol/Summer, Autumn. 2015;4(2). 